\title{
Escherichia coli in recreational water in selected sites of the river Mahaweli between Peradeniya and Katugastota
}

\author{
LRIS Liyanage ${ }^{1}$, BS Nanayakkara ${ }^{1}$, CL Abayasekara ${ }^{1}$, SU Galketiyahewage, ${ }^{1}$ \\ HTK Abeysundara ${ }^{2}$
}

Introduction and Objectives: Faecal contamination of recreational water poses a public health risk due to the possible presence of pathogens in faeces. Escherichia coli is used as an indicator of faecal contamination of water. The current study was conducted to enumerate $E$. coli in recreational water and investigate antibiotic sensitivity of the isolated E. coli.

Methods: Water samples were collected from six bathing sites along the river Mahaweli between Peradeniya and Katugastota, in two time series each, during the rainy and dry periods from August 2020 to April 2021. Samples (100 ml) were subjected to membrane filtration $(0.45 \mu \mathrm{m})$ and filters were incubated on m-FC agar at $44.5{ }^{\circ} \mathrm{C}$ for 24 hours for enumeration. Antibiotic sensitivity testing was performed for $E$. coli isolates using the disc diffusion method, for cefotaxime $(30 \mu \mathrm{g})$, ticarcillin-clavulanate $(75 / 10 \mu \mathrm{g})$, amoxicillinclavulanate $(20 / 10 \mu \mathrm{g})$, imipenem $(10 \mu \mathrm{g})$, meropenem $(10 \mu \mathrm{g})$, amikacin $(30 \mu \mathrm{g})$ and ciprofloxacin (5 $\mu \mathrm{g})$, according to CLSI guidelines.

Results: In $87.5 \%$ of bathing water samples, the $E$. coli counts exceeded the permissible levels of $235 \mathrm{CFU} / 100 \mathrm{ml}$ (U.S. EPA guidelines). In both sampling series, counts observed for the dry period were significantly lower than those for the rainy period (series 1: $p=0.00$; series 2: $p=0.02$ ). The proportions of isolates that were resistant, intermediate and susceptible, respectively, to each antibiotic were as follows; ciprofloxacin $78.6 \%, 19.8 \%$, 1.6\%; amikacin 5.2\%, 5.2\%, 89.6\%; cefotaxime 3.6\%, 15.6\%, 80.7\%; ticarcillin-clavulanate 1.6\%, 46.4\%, 52.1\%; amoxicillin-clavulanate 1.6\%, 34.9\%, 63.5\%; imipenem $0 \%$, 0.5\%, $99.5 \%$ and meropenem $0 \%, 0.5 \%, 99.5 \%$. The proportion of rainy period isolates that were resistant to at least one antibiotic was significantly higher compared to that from the dry period $(p=0.00)$, while $1.0 \%$ of the isolates were multiple drug resistant.

Conclusions: The microbiological quality of bathing water in the selected area of river Mahaweli is subject to seasonal variations. The high numbers of $E$. coli indicate faecal contamination and potential risk of faecal pathogens in water. The use of this water for bathing and recreational purposes poses significant health risks due to possible transmission of waterborne diseases and antibiotic resistant $E$. coli.

Keywords: Faecal contamination, water, membrane filtration, antibiotic resistance

Funding: University of Peradeniya (URG/2019/29/S).

\footnotetext{
${ }^{1}$ Department of Botany, Faculty of Science, University of Peradeniya, Sri Lanka

${ }^{2}$ Department of Statistics and Computer Science, Faculty of Science, University of Peradeniya, Sri Lanka

Address for correspondence:Dr BS Nanayakkara. Telephone: +94713330282 Email:buddhie@sci.pdn.ac.lk

https://orcid.org/0000-0002-7110-4216
} 